\title{
Preferential loss of collaterals from goldfish retinal axons in the optic tract is delayed by tetrodotoxin
}

\author{
E. Hartlieb and C.A.O. Stuermer \\ Friedrich-Miescher-Laboratorium der Max-Planck-Gesellschaft, Tübingen (F.R.G.)
}

(Received 6 March 1987; Revised version received and accepted 30 March 1987)

Key words: Goldfish retinal axon; Regeneration; Brachium of the optic tract; Preferential loss of collaterals; Tetrodotoxin (TTX)

Following optic nerve section (ONS) in goldfish, the right eye was repeatedly injected with tetrodotoxin (TTX) and the left eye with Ringer solution. At various survival periods after ONS, horseradish peroxidase (HRP) was applied to small groups of axons in dorsal or ventral retina in both eyes. Counts of labeled regenerating retinal axons show that $43 \pm 4.6 \%$ of regenerating axons course through the inappropriate brachium of the optic tract between 20 and 65 days after ONS. The amount of misrouted axons declines to $30 \pm 6.1 \%$ between 70 and 80 days after ONS. Under TTX blockade the reduction of misrouted axons is delayed but reaches $27 \pm 3.6 \%$ at 150 days after ONS.

When the optic nerve is sectioned in goldfish the retinal axons regenerate. In their target, the tectum opticum, they build a projection of coarse retinotopic order at early regeneration stages which refines to near normal precision around 70 days $[6,7]$.

On their way to their target regions in tectum the regenerating axons make severe pathway mistakes $[12,13,15]$. One location where pathway errors can readily be quantified is the brachial bifurcation of the optic tract. In normal fish more than $99 \%$ of all axons from dorsal retina pass through the ventrolateral brachium of the optic tract and ventral axons through the dorsomedial brachium [13]. After optic nerve section roughly $20-30 \%$ of dorsal and ventral axons travel through the incorrect brachium [12, 13]. According to a recent abstract [1] the amount of misrouted axons at the brachial bifurcation is $40 \%$ at early regeneration stages and then drops to $20-30 \%$ around 70 days, that is at survival periods when the tectal projection matures to near normal precision [9].

When the normal impulse activity of the regenerating axons is blocked with tetrodotoxin (TTX), the refinement of the retinotopic map is inhibited $[5,10]$. This report addresses the question whether TTX influences the number of incorrectly routed

Correspondence: C.A.O. Stuermer, Friedrich-Miescher-Laboratorium der Max-Planck-Gesellschaft, Spemannstrasse 37-39, D-7400 Tübingen, F.R.G. 
axons at the brachial bifurcation of the optic tract.

In common goldfish (5-7 cm body length) either the right $(n=6)$ or both the left and right optic nerves $(n=31)$ were cut under MS 222 anesthesia. In 2-day intervals, beginning at two days after optic nerve section (ONS) the right eyes were injected with TTX $(0.5 \mu \mathrm{l}$ of $0.12 \mathrm{mM}$ TTX in Ringer's solution) whereas the left (control) eyes received injections of $0.5 \mu \mathrm{l}$ Ringer. $0.7 \mu \mathrm{l}$ of $0.1 \mathrm{mM}$ TTX solution is reported to block the impulse activity of normal and regenerating axons for 2-2.5 days in fish of $10-13 \mathrm{~cm}$ body length $[4,11]$. The blockade of impulse activity after intra-ocular TTX injections was confirmed here by electro-physiological recordings from tecta of normal fish. Fish were allowed to survive between 10 and 150 days. Four to 5 days before sacrifice, horseradish peroxidase (HRP) was applied intraretinally to severed axons in either the ventro- or dorsotemporal retina. Isolated left and right optic nerves, tracts and tecta were reacted unfixed in diaminobenzidine (DAB) (5 mg DAB in $5 \mathrm{ml}$ phosphate buffer with $130 \mu \mathrm{l}$ of $10 \% \mathrm{H}_{2} \mathrm{O}_{2}$ ) for $40 \mathrm{~min}$, fixed in $4 \%$ glutaraldehyde, placed as whole mounts onto subbed slides, dehydrated through a graded series of ethanols, cleared in xylene and embedded in Permount [13,14]. Labeled axons in dorsomedial and ventrolateral brachia of the optic tract were drawn under observation with a $40 \times$ lens with the aid of a drawing tube and counted.

Few regenerating axons had passed the brachia between 10 and 15 days after ONS $[4,13]$. Their number increased steadily up to 30 days. Fiber counts were made in brachia of fish from 20 days after ONS onwards. Optic tracts with less than 15 labeled axons were discarded from evaluation. The number of optic tracts included in this study are listed in panels 2 and 5 of Table I and the survival stages after ONS in panel 1. The third and sixth panels of Table I show the mean ratio of labeled axons in incorrect brachia and their standard deviation, respectively. Panels 4 and 7 give the total amount of labeled axons over both brachia for the given survival periods.

In all animals between 20 and 150 days after ONS, labeled axons in the retinotopically appropriate brachium were more numerous than in the incorrect brachium. However, the ratio of incorrectly and correctly routed axons changed with progress in regeneration time (Table I and Fig. 1).

Brachia of control eyes: between 20-40 and 50-65 days the number of incorrectly routed axons was $42 \%$ and $43 \%$, respectively, on the control side. Between 70 and 80 days the amount of incorrectly routed axons fell to $30 \%$ and finally to $25 \%$ at 120 days (Table I). This decline is illustrated by the graph with open circles in Fig. 1. Since there was no increase of the total amount of labeled axons at 70-80 days, these results suggest that up to $18 \%$ of axons are preferentially lost from the incorrect brachium.

Brachia of TTX injected eyes: axons regenerating under TTX induced impulse blockade, (graph with stars in Fig. 1) exhibited a similar ratio of axons in the incorrect brachia (Table I) as their unblocked counterparts between $20-40$ and 50-65 days. At survival times of 70-80 days, when incorrectly routed axons diminished on the control side, TTX blocked axons in incorrect brachia remained at $43 \%$. The amount of misrouted fibers was unchanged at survival stages of 90-110 days. At 120 days, however, incorrectly routed axons were reduced to $35 \%$. One animal within this 


\section{TABLE I}

\section{NUMBERS OF AXONS IN INCORRECT BRACHIA OF THE OPTIC TRACT}

Percentage (\%) of HRP-labeled dorsal and ventral retinal axons in incorrect brachia (incorr. ax.) of the goldfish optic tract and their standard deviations (S.D.) after repeated intraocular injections of Ringer (panel 3) andTTX (panel 6) at increasing survival periods after optic nerve section (ONS) as listed in panel 1. Panels 2 and 5 give the number of optic tracts, in which the fiber counts were performed and panels 4 and 7 the total number of fibers counted.

\begin{tabular}{|c|c|c|c|c|c|c|}
\hline \multirow{2}{*}{$\begin{array}{l}\text { Days after } \\
\text { ONS }\end{array}$} & \multicolumn{3}{|l|}{ Ringer } & \multicolumn{3}{|l|}{ TTX } \\
\hline & $\begin{array}{l}\text { No. of optic } \\
\text { tracts }\end{array}$ & $\begin{array}{l}\text { \% Incorr. } \\
\text { ax. } \pm \text { S.D. }\end{array}$ & $\begin{array}{l}\text { No. of } \\
\text { axons }\end{array}$ & $\begin{array}{l}\text { No. of optic } \\
\text { tracts }\end{array}$ & $\begin{array}{l}\text { y Incorr. } \\
\text { ax. } \pm \text { S.D. }\end{array}$ & $\begin{array}{l}\text { No. of } \\
\text { axons }\end{array}$ \\
\hline $20 \quad 40$ & 7 & $42 \pm 3.4$ & 269 & 6 & $43 \pm 4.5$ & 232 \\
\hline $50-65$ & 4 & $43 \pm 4.6$ & 358 & 4 & $41 \pm 5$ & 372 \\
\hline $70-80$ & 5 & $30 \pm 6.1$ & 252 & 6 & $43 \pm 5.5$ & 356 \\
\hline $90-110$ & 8 & $29 \pm 6.1$ & 927 & 5 & $43 \pm 1.8$ & 369 \\
\hline 120 & 1 & 25 & 40 & 4 & $35 \pm 7.9$ & 535 \\
\hline 150 & - & & & 3 & $27 \pm 3.6$ & 241 \\
\hline
\end{tabular}

group had $25 \%$ of misrouted axons whereas another one had $47 \%$, indicating that axonal reduction may be faster in some individuals and slower in others. By 150 days the amount of labeled axons in the incorrect brachium was reduced to $27 \%$.

Thus, under TTX blockade, the number of regenerating axons in incorrect brachia

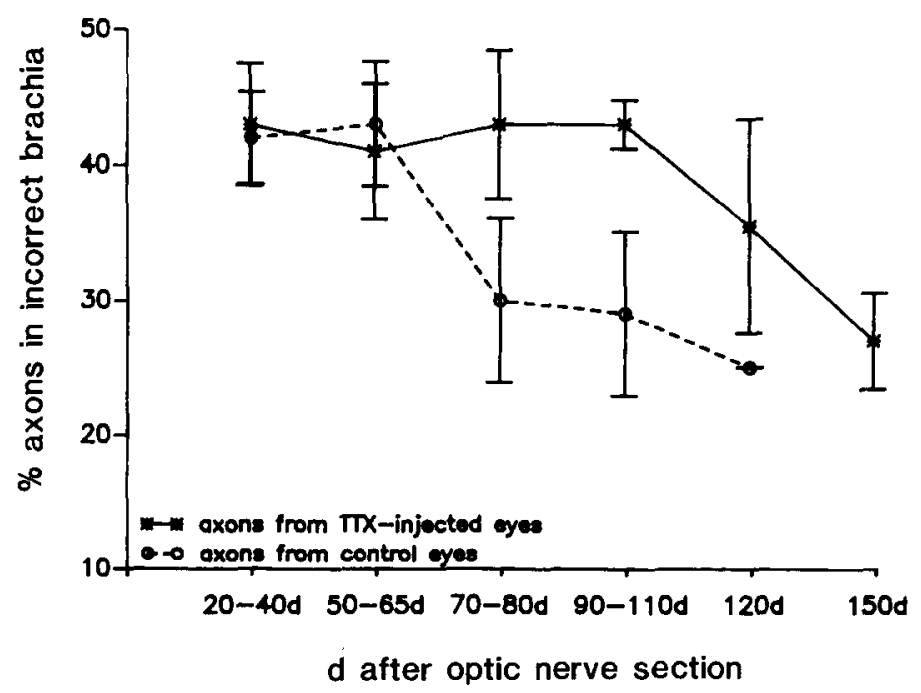

Fig. 1. Percentage of regenerating axons in incorrect brachia of the optic tract and their standard deviation, from TTX-injected and control eyes, at increasing survival time (days (d)) after ONS. Vertical bars indicate the standard deviations. 
declines to levels comparable to that found for regenerating axons with normal activity but with a delay of 50-80 days (Fig. 1).

Using fiber counts over cross-sections, an earlier publication [7] indicated that the number of regenerating axons in the optic nerve exceeds that of the normal nerve by a factor of 4 but returns to normal over a year or more. Since there is neither an augmentation of ganglion cells [7] nor reactive cell death after optic nerve section in goldfish [6] the reduction of axonal processes in the optic nerve implies that regenerating axons must have given rise to collaterals which are subsequently eliminated [7]. Our present data, consistent with earlier preliminary findings by Becker and Cook [1], indicate that collaterals within the incorrect brachium of the optic tract are preferentially abolished. We show further that the preferential loss of misrouted axon collaterals also occurs when the regenerating axons are chronically silenced by repeated intraocular injections of TTX. Although not tested in this study we have no reasons to suspect that TTX may have become ineffective to block axonal impulse activity after long regeneration periods. Chronic impulse blockades in goldfish by repeated injections of TTX have been carried out in several studies over time periods of 100 days for regenerating retinal axons $[2,4,5]$ and over 6 months for normal retinal axons [2] and return of neural activity was never observed.

It is conceivable that correctly routed axons may arrive and settle at their appropriate target region in the tectum earlier than misrouted axons and thus may gain a competitive advantage over collaterals in errant routes or axons with targeting errors. Collaterals which succeed to establish their terminal arbors and synapses at appropriate sites may become selectively stabilized whereupon misrouted collateral which have not met their target may become destabilized and subsequently eliminated [3, $10,11]$.

There is ample evidence from the neuromuscular systems [16] as well as from visual projections $[5,10]$ that the formation of precisely ordered connections is activity dependent. Polyneuronal innervation of muscles remains when the axonal activity is blocked with TTX [16]. Consistent with this evidence is the finding that the preferential reduction of axons or their collaterals from the incorrect brachium of the goldfish optic tract does not occur at times when misrouted axons or collaterals with normal activity are lost. Our present results, however, are surprising in that preferential collateral loss under TTX influence seems to be only delayed but not completely inhibited. In agreement with this result is a recent publication [8] which reports a withdrawal of misrouted axons in inappropriate parts of the superior colliculus of the rat even under axonal activity blockade with TTX.

In the light of these findings it will be most important to test whether the regenerated tectal projection in fish will undergo alterations, and possibly will improve even under the absence of activity. Such alterations of the projection may have remained undetected since chronic TTX blockades have not been carried out over more than 100 days after ONS $[5,10]$.

We like to thank Dr. Chr. Holt for comments and corrections of the manuscript. 
1 Becker, D.L. and Cook, J.E., Refinement of brachial selection by regenerating axons in the goldfish optic tract may be due to collateral loss, J. Physiol. (London), 382 (1986) 175.

2 Boss, V.C. and Schmidt, J.T., Activity and the formation of ocular dominance patches in dually innervated tectum of goldfish, J. Neurosci., 4 (1984) 2891-2905.

3 Constantine-Paton, M., The development of maps and stripes in the brain, Sci. American, 247 (1982) 54-62.

4 Edwards, D.L. and Grafstein, B., Intraocular tetrodotoxin in goldfish hinders optic nerve regeneration, Brain Res., 269 (1983) 1-14.

5 Meyer, R.L., Tetrodotoxin inhibits the formation of refined retinotopography in goldfish, Dev. Brain Res., 6 (1983) 293-298.

6 Meyer, R.L., Sakurai, K. and Schauwecker, E., Topography of regenerating optic fibers in goldfish traced with local wheat germ injections into retina: evidence for discontinuous microtopography in the retinotectal projections, J. Comp. Neurol., 239 (1985) 27-43.

7 Murray, M., A quantitative study of regenerative sprouting by optic axons in goldfish, J. Comp. Neurol., 209 (1982) 352-362.

8 O'Leary, D.D.M., Fawcett, J.W. and Cowan, M., Topographic targeting errors in the retinocollicular projection and their elimination by selective ganglion cell death, J. Neurosci., 6 (1986) 3692-3705.

9 Rankin, E.C.C. and Cook, J.E., Topographic refinement of the regenerating retinotectal projection of the goldfish in standard laboratory conditions: a quantitative WGA-HRP study, Exp. Brain Res., 63 (1986) 409-420.

10 Schmidt, J.T. and Edwards, D.L., Activity sharpens the map during the regeneration of the retinotectal projection in goldfish, Brain Res., 269 (1983) 29-39.

11 Schmidt, J.T., Edwards, D.L. and Stuermer, C.A.O., The re-establishment of synaptic transmission by regenerating optic axons in the goldfish: time course and effects of blocking activity by intraocular injection of tetrodotoxin, Brain Res., 269 (1983) 15-27.

12 Springer, A., A quantitative study of the topography within the optic tracts of goldfish following optic nerve regeneration, Soc. Neurosci. Abstr., 12 (1986) 122.

13 Stuermer, C.A.O. and Easter, S.S., A comparison of the normal and regenerated retinotectal pathway of goldfish, J. Comp. Neurol., 223 (1984) 57-76.

14 Stuermer, C.A.O., Pathways of regenerated retinotectal axons in goldfish. I. Optic nerve, tract and tectal fascicle layer, J. Embryol. Exp. Morphol., 93 (1986) 1-28.

15 Stuermer, C.A.O., Wizenmann, A. and Kelber, A., Navigation of regenerating retinotectal axons in goldfish, Soc. Neurosci., Abstr., 12 (1986) 389.

16 Thompson, W., Kuffler, D.P. and Jansen, J.K.S., The effect of prolonged reversible block of nerve impulses on the elimination of polyneuronal innervation of new-born rat skeletal muscle fibers, Neuroscience, 4 (1979) 271-281. 